\title{
The Public Valuation of Religion in Global Health Governance: Spiritual Health and the Faith Factor
}

Tine Hanrieder

\section{Introduction}

In the words of Peter Piot, former director of the United Nations Programme on AIDS (UNAIDS), the relationship between the United Nations (UN) and faith-based organizations (FBOs) is a 'history of culture clashes' (as cited in Grills, 2009, p. 507). Multilateral health institutions such as the World Health Organization (WHO), the World Bank or the United Nations Children's Fund here embody a modern 'world culture' based on the enlightenment values of science, rationalization, and liberal individualism (Barnett \& Finnemore, 2005; Boli \& Thomas, 1999). Especially in the case of health politics, this secular culture is expressed in a belief in medical progress and technical cooperation beyond political and ideological cleavages (see Staples, 2006, p. 134). However, 'religious' or 'faith-based' actors have time and again challenged the policies of secular multilateral health organizations (MHOs) on religious grounds.

Such confrontations are most prominent in the politics of HIV/AIDS, due to the stigmatization and moralization that this disease has provoked not only, but especially in religious communities. Yet, the culture clash between secular and religious claims has emerged repeatedly over the history of global health governance. ${ }^{1}$ For example, in the post-World War II decades, population control was one such contested policy field. A transnational epistemic community in favor of population policy, sponsored by private philanthropists such as the Ford and the Rockefeller Foundations, met strong opposition from the Catholic Church, which was not willing to accept birth control research and policy (Connelly 2010). This Catholic opposition meant that, for a long time, the WHO long refrained from engaging with 'human reproduction' at all (Finkle \& Crane, 1976). Another prominent example of faith-based opposition to multilateral health governance was the popular opposition that a sectarian preacher in Niger mobilized against the WHO's polio eradication campaign in 2003 (Masquelier, 2012). At present, an antagonism between religious tradition and medical progress is being articulated in the Ebola epidemic that broke out in West Africa in late 2013. A faith-

\footnotetext{
1 'Global' health governance is usually distinguished from a presumably preceding world of 'international' health governance, to indicate the growing importance of non-state actors in addition to purely interstate institutions such as the WHO. In this contribution, I will use the more encompassing term 'global health governance' for the entire spectrum of cross-border health cooperation.
} 
based insistence on church gatherings and burial rituals has clashed with biomedical attempts at halting the spread of the highly lethal Ebola virus (Abramowitz et al., 2015).

Nevertheless, multilateral organizations are increasingly seeking to integrate the specific contributions of religious groups and organizations. They do so in acknowledgement of the fact that in the context of worldwide liberalization and the retreat of the state, space has been created for faith-based service providers in public health. In African countries, for example, between 30 and 70 per cent of health services are estimated provided by FBOs (Grills, 2009, p. 509; see Section 4). MHOs like the WHO and the World Bank therefore are displaying a growing sensitivity to religious actors, support them financially, or even engage in collaborative projects (Grills, 2009). Hence, like other domains of global politics, global health is developing 'postsecular' tendencies that blur the line between the 'public political' and the 'private religious' realms (Barbato \& Kratochwil, 2009). Crossing the established boundary between the realms of religious faith and public policy has become a central challenge for global health governance. This makes it an important, but thus far neglected domain for exploring a more general problem of public justification in world politics: The question of how previously 'private' values gain acceptance as 'public' arguments. Due to its longstanding association with the non-political sphere of private belief, religion's recent inroads into the global health discourse make it a particularly fruitful case for observing how public reasons are created in global politics.

In this paper, I tackle this problem by exploring how religious values are made valu-able in the global health discourse. For this purpose, I draw on sociological valuation theory, and in particular on the pragmatist approach to justification advanced by Luc Boltanski and Laurent Thévenot $(1999,2006)$. I maintain that the creation of public worth is a practical as much as a theoretical endeavor. This holds for all values for which actors want to gain public acceptance. They need to be theoretically connected to general principles, but must also be practically connected to the social world in which their validity is claimed. This requires that values religious or secular - need to be performed in critical 'tests' with the help of shared evaluative tools (Boltanski \& Thévenot, 2006, p. 40). Public justification, thus, is based on a two-pronged evaluative operation: The connection of (religious) values to a general principle of worth, and the performance of these values through manifest objects. I will compare two attempts at mainstreaming religious values into the WHO's policies: The promotion of 'spiritual health' as an extension of the WHO's mandate in the 1980s, and the construction of 'religious health assets' for the work of MHOs since the 2000s. We will see that the vagueness and ambiguity of 'spiritual health' made many states suspicious of the term, and that the failure to create 
performances of spiritual health inhibited its public recognition in the WHO. By contrast, the creation of manifest religious health assets as worldly performances of the generic principle of 'compassion' enabled their successful inclusion in the global health discourse. This comparison emphasizes that abstraction alone is not sufficient for establishing religious norms, and shows how a focus on historical practice and devices can enhance a fuller understanding of postsecular normative dynamics. Inspired by sociological evaluation theory, I explore how decontextualization and re-contextualization are intertwined when 'transcendent' values 'go public'.

The analysis in this paper is exploratory, reconstructing two major discursive terrains on which religious values have surfaced in global health institutions. ${ }^{2}$ The paper mainly draws on public policy documents produced by and in association with MHOs: These include records of debates and resolutions of governing bodies, and research reports and policy papers that indicate the public contestation or endorsement of 'religious values' - i.e. values which are put forward by religious actors and organizations, and which are publicly declared to be of religious origin. Organizational documents express collectively negotiated and thus publicly accepted policy standards (see Neumann, 2007). Hence, in this paper, I do not speculate about whether the public endorsement of a religious value reflects the true beliefs of the actors involved, but only focus on what is collectively agreed. Likewise, I do not contribute to attempts to provide context-free and substantivist definitions of 'religion' and 'religious values'. Rather, the cases explored in this paper show how religion itself is produced in public discourses, and thus a socially constructed and historically variable term (Hurd, 2008, p. 16). I thus adopt an institutional definition of religion: If an institution, actor or value is publicly declared to be religious, it will be analyzed as religious, and the challenge is in understanding how its moral status is ascertained in the policies of presumably secular, multilateral organizations.

The paper is divided into three main sections. The following section discusses in more detail the valuation theoretical approach to public justification and specifies how this approach builds on, but also differs from, Habermasian notions of post-secular 'translation' as universalization (Section 2). I then reconstruct the failed attempts of the 1980s to make 'spiritual health' an integral part of the WHO's policies - a failure which was also due to the lack of concrete tests of the vague idea of some religious 'Factor X' (Section 3). Next, I investigate recent and more successful attempts at establishing the 'faith factor' in global public health, which are based on

\footnotetext{
${ }^{2}$ Other attempts to create religious health values might be found in biomedical circles, where, for example, the concept of 'religious coping' has gained considerable traction (see Pargament, Koenig, \& Perez, 2000).
} 
a combination of generalization and empirical tests (Section 4). The concluding section summarizes the argument and discusses the role of non-verbal performances and regional variation of religious values in global health governance.

\section{Global governance and the making of public religious values}

The United Nations system has long sustained a liberal order, which is based on Western values like human rights, democracy, the rule of law, and scientific rationality (Barnett \& Finnemore, 2005). This order is also referred to as 'secular', because religion is confined to the private sphere, and thus kept outside of multilateral institutions. However, this conception came under renewed scrutiny at the turn of the millennium, when several developments apparently questioned the secular core of global governance. These developments were in parts violent, as in the case of the 2001 Al-Qaeda attacks, which sparked new debates about religious fundamentalism - and thus about religious conflicts in world politics. But there was also a more peaceful revival of religion in different domains of (global) social policy. In the United States (US), the state-church separation began to blur domestically with the Welfare Reform Act of $1996,{ }^{3}$ and subsequently in foreign aid through the rise to power of evangelical and Pentecostal Christians. Under George W. Bush's presidency (2001-2009), the US Agency for International Development (USAID) was mandated to provide assistance for specifically religious institutions and purposes, and the President's Emergency Plan for AIDS Relief (PEPFAR) had a religiously motivated component of abstinence promotion (Clarke, 2007, pp. 82-83). Multilateral agencies like the World Bank as well developed partnerships with religious organizations (Belshaw, Calderisi, \& Sudgen, 2001). Finally, faith promotion activities by nonWestern states such as Saudi Arabia, and more generally, the rise of non-liberal powers seems to question the secular foundations of the global governance system (Clarke, 2007, pp. 83-84). Hence, the specific, post-Christian secularism of the West no longer seems to be taken for granted (Hurd, 2008).

These developments have led scholars of international norms to conceive of global institutions and the UN system as 'post-secular'. As Barbato and Kratochwil (2009) argue, liberal global governance institutions are moving toward a new order where religious claims are no longer excluded, but are entering and transforming the political discourse. The proponents of religious

\footnotetext{
3 The Act allowed for welfare service delivery by faith-based organizations, and enabled them to receive government funding (Clarke 2007, p. 82).
} 
norms may be private faith-based groups and NGOs that participate in the UN (Haynes, 2013), but also state representatives who sponsor religious norms (Bettiza \& Dionigi, 2014). These developments have fuelled scholarly interest in so-called intercultural dialogue in international politics, and in the dynamics through which religious norms are (becoming) part of the international normative order (, 2011a). To make sense of this process, Bettiza and Dionigi have put forward the concept of institutional translation. Following Jürgen Habermas' reflections on post-secularism, they conceptualize post-secular translations as a filtering process through which religious claims are decontextualized to become globally acceptable (Bettiza \& Dionigi, 2014). As I will discuss in the following, their idea of 'post-Western' institutional translation significantly widens the conceptual toolbox of IR norms research, yet its underlying 'subtractive' view of religion only provides a limited picture of the translation process (2.1). Therefore, I bring in the French pragmatist approach to justification to point out the equally important thickening process involved in public evaluation: The creative construction of worldly tests for intangible ethical values (2.2).

\subsection{Beyond a thin view of religious translation}

It is only recently that IR scholars began to theorize how religious claims are debated in world politics. Constructivist norms research in IR has long focused on the spread of liberal values across the globe (e.g. Keck \& Sikkink, 1998; Risse, Ropp, \& Sikkink, 1999). The thrust of this research is universalistic. It is based on the assumption that the better argument is ultimately on the side of Western values (Deitelhoff, 2009). Arguing against this universalism, a host of contributions emphasized that the universal application of Western norms may be contested and that 'global' norms inevitably change when they are applied in different 'local' contexts (Acharya, 2004; Wiener, 2007). Nonetheless, such adaptation processes are mostly conceived of as instances of an overall diffusion story, according to which Western values remain the source of global normative change.

Against this backdrop, Bettiza and Dionigi (2014) have heralded a 'third generation' of norms research, which shifts attention to the norm-promotion activities of non-Western actors. They focus in particular on claims by religious actors, that is, claims which have traditionally been excluded from the liberal political discourse, but which are becoming increasingly relevant in a multipolar and post-Western world society (Bettiza \& Dionigi, 2014, p. 2). Their analysis of the 'post-secular' entry of religious norms into previously secular debates is based on 
Habermas' (2006) concept of institutional translation. This concept suggests that, in order to be accepted in an official political discourse, a religious argument needs to leave some of its contextual normative luggage behind. It ought to 'transcend particularism' in order to be acceptable 'beyond the context in which it originated' (Bettiza \& Dionigi, 2014, p. 3). This, in the authors' view, is achieved through a process of abstraction. In line with Habermas's (2006, p. 10) image of an argumentative 'filter' and also citing Michael Walzer's (1994) metaphor of 'thin' versus 'thick' moral arguments, the authors theorize post-secular translations as argumentative 'thinning'. Hence, they propose that only religious arguments that are freed of idiosyncratic and particularistic legacies can have an impact on political discourses within 'secular global governance institutions' (Bettiza \& Dionigi, 2014, p. 3). The idea of postsecular translation is thus imagined as a transition from a 'thickly' integrated community of faith where religious values are not questioned, to a normatively 'thinner' but more universal public domain, a domain where only those values that can be accepted across religions pass. However, this is not a one-way adaptation. The secular interlocutors also have to learn. Translation in the Habermasian sense is a dialogical process through which the parties converge on a mutually accepted reinterpretation of a religious claim. The outcome of this dialogue will differ from its context of origin in that it is more abstract than the original norm. To be successful, it has to be marked by 'vagueness and malleability' (Bettiza \& Dionigi, 2014, p. 3). Hence to succeed, institutional translation must converge on very generic liberal values, values that can be more easily shared across cultures. This idea that vagueness is not an impediment but a condition of successful agreements has also been stressed by IR norms researchers who found that leaving some room for interpretation facilitates international agreements (see Steffek 2005).

The concept of institutional translation extends IR norms research to the neglected terrain of dialogues about religious norms in global governance institutions, and sensitizes scholars to the complex and creative dialogue that post-Western engagements require. The focus on 'filtering' and 'thinning' processes, however, only allows for a limited view of how religious claims are publicly debated. I want to point out two significant limitations of the abstraction-centric view of translation. The first limitation is that the idea of thinning presupposes an asymmetry between a more general or 'universal' secular normative order on the one side, and more 'particularistic' and culturally situated religious claims on the other. Thinning implies that religious norms originate in a shared lifeworld of believers, which is marked by contextual, cultural features, but are purified through entering general political debates. Hence, Habermasian translations are based on a dichotomy between 'pure' and general public reason, 
and 'thick' additional religious concerns. This dichotomy resembles what Charles Taylor has described as 'subtraction stories' about religion: A view according to which the secular is what remains when religion is lifted (Taylor, 2007, p. 22; see Casanova, 2011, pp. 55-56). The secular then becomes a pre-set category that does not demand further investigation, or even sociological scrutiny. Yet, as Susanne Zwingel (2012) has elaborated in the context of the global women's rights discourse, 'global' norms translation is a multi-sited and not a teleological or linear process. From the normative pluralist perspective that she adopts, the seemingly decontextualized sphere of global institutions is itself a cultural context among others, and not the hierarchical sender or impartial arbiter of 'local' cultural values (Zwingel, 2012, p. 116). By thus provincializing the values of multilateral institutions, she highlights that the liberal institutions of global governance are themselves culturally thick and situated (classically Barnett \& Finnemore, 2004), and thus to scrutinize the concrete practices through which 'global' values are forged in multilateral institutions.

This also points to the second limitation of concept of thinning, namely its neglect of the creative process of norms construction that is involved in each normative dialogue. Even though the creative construction of social values is a core claim of the constructivist research agenda, the thinning idea provides only a one-sided notion of social construction. It focuses on what is abandoned when (religious) norms travel, yet not on what is added in the process. Answering the question of how religious values are embedded in liberal institutions requires that we also analyze the 'thickening' operations that connect religious reasons to new (multilateral) contexts. If we take seriously the claim that the world is becoming multipolar and normatively pluralist, then we also need to focus our analysis on the innovative and creative component of religious arguments.

\subsection{The public construction of religious values - from abstraction to devices}

To understand the creative construction of religious values, the sociology of evaluation offers useful analytical tools. Evaluation studies focus not only on the theoretical reasoning, but also on the worldly performances that make public justification possible (cf. Lamont, 2012). This becomes evident in the pragmatist account of justification developed by Boltanski and Thévenot, which provides a decidedly empirical take on public justification as a creative social practice (Boltanski \& Thévenot, 2006; see Barnes, 2001; Kornprobst, 2014). From this pragmatist perspective, normative agreement requires both an abstract generalizing principle, 
and a manifest 'critical test' through which the agreement can be socially stabilized. To stick with the authors' terminology, a public argument is based on a justificatory 'order of worth' as much as on a 'common world' of objects, roles, and evaluative instruments through which agreement is stabilized. This notion of the 'common world' thus forces us to look at the mundane and institutional means through which actors create shared normative understandings. Such an approach is particularly suitable for capturing how previously 'private' religious values 'go public' due to its dual emphasis on context and the need for manifestation of normative agreements. $^{4}$

First, justification as a shared practice is contextual and situational. It does not demand a definite and universal answer to normative disputes, but contextually acceptable agreements (Boltanski \& Thévenot, 1999). This context-sensitivity is intrinsically tied to the insight of normative pluralism, i.e. a worldview that does not presuppose that normative conflicts can be settled by recourse to one ultimate principle. Rather, critical actors can and do draw on a diverse set of principles, and it is their creative achievement to tie a specific general value to a particular justification problem (Boltanski \& Thévenot, 2006, p. 33; see Kornprobst, 2011). In the multipolar and 'post-secular world' that IR scholars seek to understand today, it is crucial to understand how certain general principles are tied to specific contexts. Public justifications situate abstract values in concrete settings, thereby producing a contingent and particular answer to an abstract normative debate. This creative endeavor requires that 'thickening' operations and thus discursive contextualization be performed in addition to abstract debate. Contextualization is practically a routine operation in global norms development, used by both non-state norm advocates and by state diplomats. References to existing non-binding declarations like, for example, the 1978 Alma Ata Declaration on Primary Health Care, and binding norms such international human rights treaties, are commonplace in global debates. New normative claims are thereby connected to an evolving body of international norms and made historically concrete.

Second, in addition to discursive contextualization (see Payne, 2001), justification practices involve techniques of manifestation through which intangible values are made tangible. ${ }^{5}$ Boltanski and Thévenot (2006, p. 33) describe public justification as the coordinated

\footnotetext{
${ }^{4}$ Evidently, the concepts of 'public' and 'private' are themselves not stable but take on different meanings in different contexts (cf. Casanova 1994, pp. 40-66). In this article, I adopt an institutional perspective and consider that public values are those that are accepted in multilateral institutions.

${ }^{5}$ See also Birnbaum (2015) on techniques of making religion measurable (or 'recognizable') in the case of postcolonial nation-building.
} 
performance of critical 'tests'. Through the creation and performance of manifest tests, abstract ideas are transferred into a shared evaluative repertoire that stabilizes meaning and moral worth. In doing so, people involve worldly objects or 'things' in their arguments - artifacts such as technologies of visualization and measurement, symbols, or institutional roles - on which public agreement can rest (Boltanski \& Thévenot, 2006, p. 40). This also applies to otherwise private and esoteric questions of faith and spirituality. As the authors elaborate with regard to the moral status derived from 'inspiration', the task of publicly evaluating what otherwise remains a private virtue is particularly challenging. To make this possible, specific symbols and role expectations are brought into play that allow for a person's publicly recognized status as 'inspired' (Boltanski \& Thévenot, 2006, pp. 83-88; see below, footnote 21). Hence, the practice view of public justification as social evaluation makes it clear that thinning and thickening are always intertwined in public discourse. Next to invoking a general principle on which agreement can be based, agents construct a practical test that performs a shared value in a specific context, or use historical analogies are shortcuts to make abstract values concrete. Devices and indicators are central to the construction of shared values that can be publicly accepted. ${ }^{6}$ Evaluative devices are regularly used and produced in global politics. For example, the bureaucracies of international organizations, state agencies, or well-equipped non-state organizations develop assessment tools for measuring values such as political freedom, transparency, economic development or stability, and they increasingly use rankings that operationalize what are 'good' national health systems, 'creditworthy states' or 'environmentally sustainable' commodities (Cooley \& Snyder, 2015; Dingwerth \& Pattberg, 2009). They also develop new elaborate rituals such as the practice of 'truth telling' as a means to perform 'justice' and 'peace' (Renner, 2013). Thereby, 'universal' values such as peace, farness or sustainability, which would otherwise remain thin and vague, take on manifest meanings that can be measured and drawn on in real world interactions.

This operation of making turning abstract values into social realities is of particular relevance to the global recognition of 'transcendent' religious norms. In the following, I will therefore use the dual lens of 'thin' abstraction plus 'thick' contextualization to reconstruct two attempts to translate religious values into global health institutions: The debate about adding 'spiritual health' to the mandate of the WHO, which took place in the 1980s (Section 3), and the attempt to establish faith as a determinant of health, which started in the new millennium (Section 4).

\footnotetext{
${ }^{6}$ Of course, the use of devices can also fail and they do not automatically stabilize normative agreement. To borrow from Maria Birnbaum's terminology, they help to make values 'recognizable' (or acceptable) yet they do not guarantee their acceptance (Birnbaum 2015).
} 
In the first case, vagueness alone proved insufficient to make spiritual health acceptable. In the second, the manifest evaluative repertoire of 'religious health assets' elevated the moral status of faith in multilateral health institutions.

\section{Spiritual health and the failure to mainstream 'Factor $X$ '}

During the first decades of its existence, the WHO did not explicitly endorse religious values. It followed a secular and modernist agenda that was formulated by medical and public health professionals (Staples, 2006, p. 134). The organization also upheld its abstention from religion when collaborating with religious actors, for example in its work on the primary health care (PHC) agenda. PHC had become the WHO's main policy paradigm in the early 1970s, as the organization shifted its attention from high-tech biomedicine to basic, community-driven and inter-sectoral health policies. Notably, the WHO designed this policy shift in close collaboration with a religious actor, namely the Christian Medical Commission of the World Council of Churches (Litsios, 2004). Furthermore, the WHO's director-general Halfdan Mahler propagated the PHC agenda and its slogan 'Health for All by the Year 2000' with 'missionary zeal' (Cueto, 2004, p. 1865). In retrospect, Mahler (2008) would consider the PHC movement and its legendary International Conference on Primary Health Care, which was held in Alma Ata in 1978 as an 'intellectual and spiritual awakening'. Still, he also stressed that 'spiritual' here was not to be understood 'in the religious sense [...] but in the sense that people wanted to accomplish something great' (Mahler, 2008). In fact, the PHC policies that were developed in the 1970s did not refer to questions of faith or religion. They encouraged the deployment of simply trained health workers, prevention and education measures, and community and rural development, and thus were designed as secular social policies. ${ }^{7}$

The secular approach of PHC was problematized, however, when a group of norm proponents of different religious backgrounds attempted to make 'spiritual health' an integral part of the PHC agenda as well. Yet as we will see in the following, the advocacy for 'spiritual health' got lost in a process of abstraction. Its proponents failed to provide manifest tests of what was also called 'Factor X', and thus did not manage to establish spiritual health as a component of the PHC agenda.

\footnotetext{
${ }^{7}$ On the origins and substance of PHC cf. Cueto (2004) and Litsios (2002).
} 


\subsection{The spiritual 'Factor $X$ ' and its inter-faith alliance}

The need for the WHO to address questions of spiritual health was first raised by the Indian delegate to the Executive Board in 1978, the year when the international PHC conference was to be held in Alma Ata, Kazakhstan. The delegate, Desh Bandu Bisht, suggested amending the definition of health provided by the WHO constitution, which reads that health is 'a state of complete physical, mental and social well-being and not merely the absence of disease or infirmity' (WHO, 2006). Drawing on 'Indian thinking through the ages', Bisht argued that the WHO definition of health should be enlarged to include the 'spiritual' dimension, because otherwise there would be hardly any difference between the vitality of animals ('a pack of wolves') and the higher and 'more subtle' faculties of humans (Bisht, 1985, p. vii). Still, the delegate also conceded that the term 'spiritual' might not be equally acceptable across cultures. He therefore proposed that for the time being, the missing dimension should be referred to as a hypothetical 'Factor X' (Bisht, 1985, pp. 5-10). While this proposal was not taken up at the Board's 1978 session (Al Khayat, 1997, p. 224), it was followed up by a larger group of countries who jointly sponsored a resolution at the 1983 World Health Assembly (WHA), the WHO's annual member state meeting and supreme decision making body.

The draft resolution of 1983 was sponsored by a religiously diverse, though dominantly Islamic coalition of 22 countries. ${ }^{8}$ It was entitled 'The spiritual dimension in health care programmes' and stated that a 'spiritual dimension' was not only implicit in the WHO definition of health, but also crucial for attaining the goals of PHC and Health for All (Al Khayat, 1997, pp. 221222). The draft resolution therefore 'requested' that the director-general mainstream spiritual health in the PHC approach, that is, he was asked 'to take the spiritual dimension into consideration in the preparation and development of primary health care programmes aimed at the attainment of the goal of health for all by the year 2000' (Al Khayat, 1997, p. 222). This proposal thus amounted to extending the mandate of the WHO to the provision of spiritual health. It was first discussed in the WHA's Committee A, which is responsible for policy matters, and then brought to the plenary assembly. These discussions, however, were marked by confusion and disagreement about the meaning of 'spiritual health', an ambiguity that made many country delegations suspicious of the concept's value for policy making. On the one side, delegates from the sponsoring countries such as Kuwait and Yemen emphasized that spiritual

\footnotetext{
${ }^{8}$ The proponents of the resolution were Bahrain, Botswana, Chile, Democratic Yemen, Egypt, Kenya, Kuwait, Malawi, Mauritania, Morocco, Oman, Qatar, Saudi Arabia, Somalia, Sudan, Swaziland, Syrian Arab Republic, Tunisia, United Arab Emirates, Venezuela, Yemen, and Zambia (Al Khayat 1997, p. 221). Curiously, India was not a co-sponsor, but participated in the WHA debates about the draft resolution, see below.
} 
health was an important antidote to the 'materialism' of their times (Al Khayat, 1997, pp. 222, 223), and a delegate of the United Arab Emirates stressed that the resolution was relevant to individuals of any religious belief (Al Khayat, 1997, p. 223). On the other side, opposing delegations, for example from the Soviet countries, found any potential reference to 'religious aspects' unacceptable for countries where the state and the church had been deliberately separated (A1 Khayat, 1997, p. 222). Prompted by the Indian delegate to give his opinion on the matter, the director-general proposed to refer the matter to the Executive Board to allow for an in-depth discussion and develop a consensus on the wording (Al Khayat, 1997, p. 224). Still, since a majority of the committee members voted in favor of the draft resolution, it was further debated in the plenary assembly.

In the WHA's plenary however, the confusion and disagreement about the purpose of the resolution proved insurmountable. For example, a delegate from Mozambique pointed out that all the potential meanings of 'spiritual health' put forward in the discussions - among others 'mental health; medical ethics; respect for each people's culture; health education; and so on' - were already part of the PHC agenda (WHO Regional Office for the Eastern Mediterranean [WHO ROEM], 1996, p. 270). By contrast, the specific value of 'spiritual' health had not yet been explicated, so that the concept was not 'mature enough' to be agreed upon (WHO ROEM, 1996, p. 270). Other delegates, for example from Italy and from Gabon, also held that further clarification was needed because at that point in time, the concept was hard to comprehend at all (WHO ROEM, 1996, p. 272). Hence, 'vagueness and malleability' (Bettiza \& Dionigi, 2014 , p. 3) turned out to be an obstacle to public consensus, and led to a postponement of the matter to next year's Executive Board (WHO ROEM, 1996, p. 274). ${ }^{9}$

\subsection{Watering down and referring back to the periphery - the failure to globalize 'Factor X'}

By the time the Executive Board reconsidered the spiritual health issue, the director-general had developed a compromise formula. In his three-page background paper 'Global strategy for Health for All be the Year 2000: The spiritual dimension' the DG elaborated on the concept 'spiritual', associating it with 'a phenomenon that is not material in nature but belongs to the realm of ideas that have arisen in the minds of human beings, particularly ennobling ideas' (WHO, 1998b, pp. 1, emphasis in original). The paper suggested that political ideals could well

\footnotetext{
${ }^{9}$ Of 113 members present and voting on the decision to postpone the matter, 80 voted for, 33 against, and 12 abstained (WHO ROEM 1996, p. 274).
} 
lead to 'vast material changes', for example, the abolition of slavery - or the PHC-related strategy of Health for All, which was informed by 'such humane qualities as a sense of decency, empathy with the world's health [sic] underprivileged, compassion, and the desire for social justice regarding health' (WHO, 1998b, p. 2). The document avoided, however, proposing specific additional measures for furthering spiritual health through the PHC agenda. To the contrary, the DG emphasized that while "the material component [of PHC] can be "provided", the non-material or spiritual one cannot' (WHO, 1998b, p. 3). Thereby, the DG outright rejected the draft resolution's 'request' that he integrate spiritual values within the WHO's Primary Health Care strategies. The Executive Board endorsed this document without further public discussion and forwarded it to the 1984 Assembly (WHO, 1985, p. 5).

The 37th WHA adopted a resolution that followed the wording proposed by the secretariat, and that endorsed the points made in the DG's report. Instead of mainstreaming spiritual health in the WHO's policies, the resolution merely 'invite[d]' member states to 'consider including in their strategies for health for all a spiritual dimension [...] in accordance with their cultural and religious patterns' (WHO, 1985, pp. 5-6). Thereby, the spiritual dimension was effectively deflected by the WHO secretariat and referred back to the countries, which were free to follow up on the issue, or not.

In summary, the fate of this initiative shows that despite support across religious denominations, the vague idea of some 'Factor X' proved too thin to successfully translate spirituality into the central organs of the WHO. Its vagueness and ambiguity did not make it easier to add spiritual health to the WHO mandate. To the contrary, it fueled suspicion of the meaning and purpose of the term, and many states refused to support what looked like an open-ended and risky norm creation process. In the years that followed, a few decentralized initiatives in two of the WHO's six regional organizations pursued the agenda of spiritual health further. In the Southeast Asian region, a workshop held in Bangalore in 1985 explored the health value of 'Factor X' from the perspective of different faiths. In the 1990s, the WHO's Eastern Mediterranean regional office launched a publication series entitled 'Health Education through Religion' (e.g. Al Khayat, 1997; Ottersen et al., 2014). The series was supported by the so-called Amman Declaration on 'Health Promotion through Islamic Lifestyles', which was jointly published by the regional office and the Islamic Educational, Scientific and Cultural Organization (WHO ROEM, 1996). The region also sponsored another attempt at extending the WHO definition of health to include a 'dynamic' and 'spiritual' dimension (WHO, 1998a, p. 2; see WHO, 1998b, pp. 40-43). Yet again, the initiative was not taken up, and the WHO definition of health has remained 
unchanged. Until today, the WHO headquarters and its central governing bodies have shied away from making spiritual health a part of WHO policy. Factor X has thus far not been upstreamed to the level of centralized policy-making.

It is, of course, only with the benefit of hindsight that we can see how a lack of specification and 'thickening' lead to the dismissal of 'spiritual' health as part of the WHO's work. It remains a counterfactual question, whether more resourceful norm entrepreneurs would have come up with a more successful campaign than the diffuse promotion of 'Factor $\mathrm{X}$ '. ${ }^{10}$ We thus do not know whether it would have been possible at all to overcome the doubts of many member states through an interpretation of spiritual health that was acceptable to the sponsors and to the skeptics alike, and to build a sufficiently powerful coalition through a differently interpreted 'spiritual health' norm. Here, a first step can only consist of exploring the norm construction process in its specific historical context (see introduction to this special issue): Quite in line with Habermas' 'translation' proposition, the skeptical states were indeed suspicious that unwanted 'religious' baggage might travel with the unspecific concept of 'spiritual health' (WHO, 1985). Vagueness looked risky because too open for interpretation, not like an opportunity to strike a 'cheap' and unspecific agreement that no one is against, and that hurts no one at the same time. Yet, from an interpretive viewpoint, what this debate about 'spiritual health' also reveals is that in order to convince the skeptics and diffuse their suspicions, a particular rather than a universal interpretation must be offered: An interpretation that rules out disputed content through disambiguation and a more concrete manifestation of the meaning of religious health values. Such an operation of making religious health values more specific and thus particular can be observed in the more recent agenda of evaluating the 'faith factor' in global health.

\section{Tests of religion's health value: Religious health assets and the faith factor}

The 2000s saw the making of new concepts through which religious values could be acknowledged in global health policy. At a time of growing interest in the role of religion in world politics in general, and in development in particular, a range of formalized interfaith initiatives started contributing to the renewed translation effort. One important player here was the World Faith Development Dialogue (WFDD), founded in 1999 through a joint initiative of

\footnotetext{
${ }^{10}$ I thank an anonymous referee for raising this important question about the general prospects for a spiritual health campaign in the 1980s' constellation.
} 
the Archbishop of Canterbury and World Bank President James D. Wolfensohn. Starting as an informal meeting between World Bank experts and representatives of nine major world religions, the WFDD quickly grew into a formal institution in which myriad religious organizations and development agencies were involved. Its governance was soon decoupled from the World Bank to ensure the independence of both institutions (Marshall, 2001, pp. 350353). The WFDD serves as a forum for exchanging ideas about poverty, development or health, and about approaches to dealing with these issues by bringing in religious perspectives. In collaboration with the Tony Blair Faith Foundation, the WFDD has developed concepts for evaluating faith work in global health, particularly in Africa (World Faiths Development Dialogue [WFDD], 2012). This endeavor has been joined by the Center for Interfaith Action on Global Poverty (see CIFA, 2010), and by the African Religious Health Assets Programme (ARHAP), which was created in 2002 and re-launched as the International Religious Health Assets Programme (IRHAP) in 2012. ${ }^{11}$

These initiatives undertook studies and delivered reports to multilateral organizations such as the WHO (ARHAP, 2006), and to major Western philanthropists such as the Bill and Melinda Gates Foundation (Schmid, Thomas, Olivier, \& Cochrane, 2008), in order to make religion valu-able for multilateral organizations working on global health. They did so through a detailed mapping of tangible health services provided by religious entities (4.1), and by creating cognitive tools for testing the worth of the intangible 'faith factor' in public health (4.2).

\subsection{The public value of religious health assets}

Attempts to re-value the worth of religion in global health have mostly been centered on the African continent, and especially the countries in sub-Saharan Africa. Donors and multilateral organizations have become interested in the health activities of religious entities, ${ }^{12}$ because these apparently make up an important share of health services in these regions, and play an important part in the life worlds of 'the poor' (Narayan, 2000). Interfaith initiatives have strongly contributed to documenting the presence of health services provided by religious entities, by geographically mapping infrastructures and conducting surveys about the role of religion in the health concerns of individuals. For example, ARHAP provided a detailed study

\footnotetext{
11 See http://www.irhap.uct.ac.za/about_history.php (accessed 27 May 2015).

12 The term 'religious entities' refers to formal religious organizations, but also to self-organized groups and in some cases individuals (cf. ARHAP 2006, p. 43).
} 
of so-called 'health-promoting religious assets' in Lesotho and Zambia, focusing in particular on HIV/AIDS programs in these countries (ARHAP, 2006, p. 1). The focus on AIDS was an important move, because more than any other domains of health work, the HIV/AIDS pandemic had long been associated with religiously motivated stigmatization, denial, or the refusal of religious health agencies to distribute condoms.

The geographical mapping exercise of ARHAP focused on 'tangible' religious health assets or RHAs, meaning the physical 'infrastructures' provided by religious organizations, groups and individuals. These are, for example, hospitals, health centers and private practices, but also schools and other education providers and entities engaged in prevention and counseling (ARHAP, 2006, pp. 41-45). While containing caveats due to missing data and need for further research, the study concluded that on average, 40 percent of health services in sub-Saharan were provided by religious entities (ARHAP, 2006, p. 46) - a number that is in line with earlier studies of African countries, which came up with figures between 30 and 70 percent. ARHAP's detailed mapping exercise contributed to making visible the health work of religious actors, which is often not accounted for in public budgets due to their independent organization and funding. This mapping was endorsed in a $2008 \mathrm{WHO}$ publication that stressed the importance of faith-based organizations for primary health care (WHO, 2008). ${ }^{13}$

Hence, the numbers and geographical maps helped to document the 'public value' of religious health work, especially in countries where governmental services were utterly deficient. The WHO secretariat endorsed this value by proposing policies on how local and national governments could systematically tap this public value and partner with religious actors to deliver PHC (WHO, 2008, pp. 19-22). ${ }^{14}$ This recognition, though not reflected in an official WHA resolution, still goes far beyond the strictly secular stance that the WHO displayed in the debates about spiritual health outlined above. However, the focus on material infrastructures and services keeps a safe distance from religious ideologies and normative claims, and thus from what religious actors refer to as their 'intangible' RHAs. Recognizing material services provided by churches, thus, does not question the secular values $n$ the basis of which this recognition is granted. Yet, the translation process went further I the following, through the invention of specific devices for assessing religious worth in global health. For, in addition to

\footnotetext{
13 This publication complemented the WHO's 2008 World Health Report Primary Health Care - Now More Than Ever (Schmid, Thomas, Olivier, \& Cochrane 2008), which sought to revive the PHC concept 40 years after the Alma Ata conference.

${ }^{14}$ Among other assets, partnerships with FBOs were for example conceived as means to complement government services, bring in external donor money, or tap community resources and capacities (WHO 2008, p. 19).
} 
the physical mapping, the RHA agenda has produced new evaluative tools through which the intangible value of religion for health is made visible in secular organizations.

\subsection{Creating tests of the 'faith factor'}

To assess the value of religious health services, an increasing number of studies is has sought proof not only of their general effectiveness and functionality, ${ }^{15}$ but of religion's 'comparative advantage' vis-à-vis secular health services. These endeavors have been undertaken by interfaith agencies and WHO staff, but most importantly by World Bank staff, who have developed specific indicators and measurements of the faith factor (e.g. Coulombe \& Wodon, 2013; Narayan, 2000; Olivier \& Wodon, 2012). Their notion of the distinct added value of religious services here goes beyond the idea that they enhance the 'cultural sensitivity' (Schmid et al., 2008, p. 24) of medicine. Rather, the focus is on the so-called 'intangible' benefits of religions for health. A host of partially overlapping lists of such advantages has been put forward, which thereby aim to conceptualize the intangible health value of religion. The proposed assets here range from the values of 'prayer', 'commitment/sense of duty', or a 'sacred space in a polluted world' (Schmid et al., 2008, p. 23), to claims that religion provides a distinctly 'holistic perspective on human wellbeing' and that faith leaders enjoy a particular 'credibility and trust' in their communities (CIFA, 2010, p. 4; see also McGilvray, 1981). Hence, endeavors have intensified to estimate the value of the 'faith factor' for public health.

These attempts to translate the health value of religion for secular MHOs have involved parallel thinning and thickening operations. On the one hand, general concepts have been developed that serve as abstractions from specific faiths and particular denominations, thus proposing a generic notion of 'religion' that is believed to be applicable to different faiths and communities - and that distinguishes religion from secular, biomedical approaches to health. In particular, the general ideal of 'compassion' for the sick and vulnerable has been singled out as the generic value of religion for health - and as a value that faith-based actors display to an even greater extent than other medical or humanitarian professionals. For example, in the 2008 WHO document on religious actors and primary health care, 'compassion' is identified as 'the universal attribute of faith' (WHO, 2008, p. 11). Each of the major religions, it is argued, 'recognizes the care of others as a divine calling' (WHO, 2008, p. 11). Evidently, such an altruistic inspiration is not tangible in itself, because is refers to inner motivations and spiritual

\footnotetext{
15 An overview of general effectiveness studies is provided in (WFDD 2012, pp. 56-64).
} 
attitudes. Thus, to enable a public valuation of religion's transcendent values, a range of studies has 'thickened' the concept through various indicators. In particular two indicators have been emphasized in recent studies. First, these studies test faith-based compassion via the 'greater commitment' of health workers or volunteers in religious facilities (cf. WFDD, 2012, pp. 6768; see WHO, 2008, p. 11). World Bank experts have, for example, compared the wages of health staff in religious and non-religious entities - and found preliminary evidence that at least in Ghana, religious commitment seems to be at work, because in religious facilities staff were paid below the market wage. Nevertheless, and also despite the fact that the religious facilities also charged less fort their services than other facilities, their health indicators were aboveaverage (Narayan, 2000). Hence, commitment is valued as a distinct 'faith factor' that demonstrably improves the quality of health services. ${ }^{16}$

A related second specification of the faith factor points out that compassion means caring for the poor. Hence, the 2003 World Bank study by Reinikka and Svensson stressed that religious service providers in Uganda provided more services to the poor, at lower prices, but without compromising on quality (Narayan, 2000). The idea that religious actors 'have special reach to the poor, rural, and other vulnerable groups' (WFDD, 2012, p. 66) has now become firmly established among global health and development actors. It informs the policies and selfpresentations of agencies such as PEPFAR and World Vision (WFDD, 2012, p. 66), and underlies ongoing research efforts at measuring and quantifying the faith factor in global health (Coulombe \& Wodon, 2013). While it is not predefined that an 'effect' of this factor will be demonstrated in each study of religious health assets, the existence of a manifest test of these assets helps to give them reality, and make religion a public value in global health.

Hence, through such measurements of the abstract ideal of compassion, the 'religious value' of compassion has become public and performable in global health. The idea that religious inspiration can improve health services has thereby become acceptable for MHOs, and it has begun to replace the ingrained suspicion of religion as an irrational factor that jeopardizes medical progress. This re-valuation has been based on abstraction as much as on particularization. The creation of a generic, 'interfaith' concept of compassion as defining an

\footnotetext{
16 Notably, this idea of using intrinsic motivation and commitment for public tests of religious values is similar to the tests of 'inspiration' that Boltanski and Thévenot (2006, p. 88) describe in their reflections on the inspired order of worth: Inspired actors here are those who do not strive for mundane rewards and not even 'recognition from others', but who pursue their ideals 'without concern for other people's opinion'. While the preparedness to work below market wage is not the same as renouncing any social recognition, it nevertheless points to a person's source of inspiration outside established remuneration schemes. In a sense, it refers to the 'spiritual health' of the health providers and their above-average altruism.
} 
entire 'faith sector' here has been as important as specific tests of this compassion in concrete health services. This public valuation of the faith factor in global health thus illustrates how thinning and thickening operations are intertwined in post-secular translations of religious values for global public policy.

\section{Conclusion}

This paper has investigated the public evaluation of religion in global health governance. I have analyzed policy discourses in and around multilateral organizations through which the health value of religion has entered the secular domain of medicine and public health, focusing in particular on two such discourses: The debates about including the provision of 'spiritual health' in the mandate of the WHO since the 1980s, and debates about the value of the 'faith factor' in religious health services, which started in the new millennium. Combining the Habermasian idea of post-secular translation with pragmatist approaches to evaluative performances, I have argued that the public valuation of religion is a two-pronged process. On the one hand, it is based on the abstractions through which religious values are transformed into generic concepts that are compatible with secular discourses. On the other hand, it requires concretizations through which religious values become manifest and 'testable' in public debates. Only when the two operations of thinning and thickening are combined can previously private religious values become part of public justification. This also explains why the abstract concept of spiritual health has gained far less traction than concrete assessments of the faith factor in public health. The previously vague 'Factor $\mathrm{X}$ ' of the spiritual health debate has become a measurable and valu-able concept through new measurements of the 'faith factor'.

The analysis provided here implies that post-secular valuations are eminently creative and potentially transformative processes. We have seen that to forge public understanding about religious values, new generic understandings of 'religion' as 'compassion' have been created, and new tests have been designed that specify the meaning of compassion and inspiration in global health. Hence, the concepts of religion and faith are themselves not fixed or primordial categories, but they gain their meaning and reality through ongoing justification efforts. In the words of practice theory, the value of religion in global (health) governance is a creative performance.

While this paper has centered on global policy debates as they unfolded in policy documents in and around multilateral organizations, future studies could extend this perspective to other sites, 
and to other performances of religions values. For example, the reconstruction of the spiritual health debate in the WHO has shown the inter-regional variation of this debate. While the WHO's regional offices in South-East Asia and the Eastern Mediterranean have taken up the problem of spiritual health in regional contexts, other regions and the WHO's headquarters have abstained from engaging with the concept. Hence, different regional and institutional sites might produce different variations of religious themes in public policy, a dimension which has not been captured in this paper's focus on IOs' metropolitan headquarters and centralized policy discourses. Given that public valuations are contextual and situated performances, exploring this variety can further contribute to understanding the careers of post-secular values in global health.

Likewise, future studies should explore performances other than textual performances and verbal constructions of critical tests of religious worth. Inter-religious and 'religiondevelopment' dialogues are also tempo-spatial performances, for example, in globally broadcasted summits of faith and development leaders. These are publicly staged and entail ceremonies, rituals, and visual representations of what religion, health, or development entail. Visual analyses of these performances and their presentation through pictures or films can thus productively complement the text-based approach presented in this article. Such an approach can help us to identify how the location of religious and secular actors in public space and their physical association with value-laden symbols construct the public value of religion. An extension of the analysis to the visual dimension of public justification can generate insight into the ways in which physical performances support, complement, or maybe also counteract the creation of religious values on the global policy stage. 


\section{References}

Abramowitz, S. A., Bardosh, K. L., Leach, M., Hewlett, B., Nichter, M., \& Nguyen, V.-K. (2015). Social science intelligence in the global Ebola response. The Lancet, 385(9965), 330. doi:10.1016/S0140-6736(15)60119-2

Acharya, A. (2004). How Ideas Spread: Whose Norms Matter? Norm Localization and Institutional Change in Asian Regionalism. International Organization, 58(2), 239-275.

African Religious Health Assets Programme. (2006). Appreciating Assets: The Contribution of Religion to Universal Access in Africa. Report for the World Health Organization. Cape Town: African Religious Health Assets Programme. Retrieved from http://www.irhap.uct.ac.za/downloads/ARHAPWHO_entire.pdf

Al Khayat, M. H. (1997). Environmental Health: An Islamic Perspective (The Right Path to Health: Health Education through Religion). Alexandria: WHO Regional Office for the Eastern Mediterranean.

Barbato, M., \& Kratochwil, F. (2009). Towards a post-secular political order? European Political Science Review, 1(03), 317. http://dx.doi.org/10.1017/S1755773909990166

Barnes, B. (2001). Practice as Collective Action. In T. R. Schatzki, K. Knorr Cetina, \& E. von Savigny (Eds.), The Practice Turn in Contemporary Theory (pp. 25-35). New York: Routledge.

Barnett, M. (2011). Another Great Awakening? Religion and International Relations Theory. In J. Snyder (Ed.), Religion and International Relations Theory (pp. 91-114). New York, NY: Columbia University Press.

Barnett, M., \& Finnemore, M. (2004). Rules for the World: International Organizations in Global Politics (1. print.). Ithaca, NY: Cornell University Press.

Barnett, M., \& Finnemore, M. (2005). The Power of Liberal International Organizations. In M. Barnett \& R. Duvall (Eds.), Power in Global Governance (pp. 161-184). Cambridge: Cambridge University Press.

Belshaw, D., Calderisi, R., \& Sudgen, C. (Eds.). Faith in Development: Partnership Between the World Bank the the Churches of Africa. Oxford, UK, Irvine, CA, Akropong Akuapem: Regnum Books International.

Bettiza, G., \& Dionigi, F. (2014). How do Religious Norms Diffuse? Institutional Translation and International Change in a Post-secular World. European Journal of International Relations, online first, 1-26.

Birnbaum, M. (2015). Becoming Recognizable : Postcolonial Independence and the Reification of Religion (Doctoral dissertation, European University Institute, Italy). Retrieved from http://hdl.handle.net/1814/35441

Bisht, D. B. (1985). The Spiritual Dimension of Health, including Summary Proceedings of the National Workshop held at Bangalore in February 1985. Delhi: Directorate General of Health Services, Government of India.

Boli, J., \& Thomas, G. M. (Eds.). (1999). Constructing World Culture: International Nongovernmental Organizations since 1875. Palo Alto: Stanford University Press.

Boltanski, L., \& Thévenot, L. (1999). The Sociology of Critical Capacity. European Journal of Social Theory, 2(3), 359-377.

Boltanski, L., \& Thévenot, L. (2006). On Justification: Economies of Worth. Princeton, NJ: Princeton University Press.

Casanova, J. (1994). Public Religions in the Modern World. The University of Chicago Press. 
Casanova, J. (2011). The Secular, Secularizations, Secularism. In C. Calhoun, M. Juergensmeyer, \& J. van Antwerpen (Eds.), Rethinking Secularism (pp. 54-74). Oxford University Press.

CIFA. (2010). Many Faiths, Common Action: Increasing the Impact of the Faith Sector on Health and Development. Retrieved from http://www.partnershipforfaithanddevelopment.org/wp-content/uploads/2013/09/ManyFaiths-Common-Action-Report1.pdf

Clarke, G. (2007). Agents of Transformation? Donors, Faith-based Organisations and International Development. Third World Quarterly, 28(1), 77-96.

Connelly, M. (2010). Fatal Misconception: The Struggle to Control World Population. Cambridge, MA and London: Belknap Press of Harvard University Press.

Cooley, A. \& Snyder, J. (2015). Ranking the World: Grading States as a Tool of Global Governance. Cambridge, UK: Cambridge University Press.

Coulombe, H., \& Wodon, Q. (2013). Mapping Religious Health Assets: Are Faith-inspired Facilities Located in Poor Areas in Ghana? Economic Bulletin, 33(2), 1615-1631.

Retrieved from http://www.accessecon.com/Pubs/EB/2013/Volume33/EB-13-V33-I2P151.pdf

Cueto, M. (2004). The Origins of Primary Health Care and Selective Primary Health Care. American Journal of Public Health, 94(11), 1864-1874.

Deitelhoff, N. (2009). The Discursive Process of Legalization: Charting Islands of Persuasion in the ICC Case. International Organization, 63(1), 33-65.

Dingwerth, K. \& Pattberg, P. (2009). World Politics and Organizational Fields: The Case of Transnational Sustainability Governance. European Journal of International Relations 15(4), 707-743.

Finkle, J. L., \& Crane, B. B. (1976). The World Health Organization and the Population Issue: Organizational Values in the United Nations. Population and Development Review, 2(3/4), 367-393.

Grills, N. (2009). The Paradox of Multilateral Organizations Engaging with Faith-based Organizations. Global Governance, 15(4), 505-520.

Habermas, J. (2006). Religion in the Public Sphere. European Journal of Philosophy, 14(1), $1-25$.

Haynes, J. (2013). Faith-based organisations at the United Nations. EUI Working Paper, RSCAS 2013/70. Retrieved from http://cadmus.eui.eu/bitstream/handle/1814/28119/RSCAS_2013_70.pdf?sequence=1

Hurd, E. S. (2008). The Politics of Secularism in International Relations. Princeton, Oxford: Princeton University Press.

Keck, M., \& Sikkink, K. (1998). Activists Beyond Borders: Advocacy Networks in International Politics. Ithaca, NY: Cornell University Press.

Kornprobst, M. (2011). The Agent's Logics of Action: Defining and Mapping Political Judgement. International Theory, 3(1), 70-104.

Kornprobst, M. (2014). From Political Judgments to Public Justifications (and Vice Versa): How Communities Generate Reasons Upon Which to Act. European Journal of International Relations, 20(1), 192-216.

Lamont, M. (2012). Toward a Comparative Sociology of Valuation and Evaluation. Annual Review of Sociology, 38, 201-221.

Litsios, S. (2002). The Long and Difficult Road to Alma Ata: A Personal Reflection. International Journal of Health Services, 32(4), 709-732. 
Litsios, S. (2004). The Christian Medical Commission and the Development of the World Health Organization's Primary Health Care Approach. American Journal of Public Health, 94(11), 1884-1893.

Mahler, H. (2008). Primary Health Care Comes Full Circle: An Interview with Dr Halfdan Mahler. Bulletin of the World Health Organization, 86(10), 747-748.

Marshall, K. (2001). Development and Religion: A Different Lens on Development Debates. Peabody Journal of Education, 76(3/4), 339-375.

Masquelier, A. (2012). Public Health or Public Threat? Polio Eradication Campaigns, Islamic Revival, and the Materialization of State Power in Niger. In H. Dilger, A. Kane, \& S. A. Langwick (Eds.), Medicine, Mobility, and Power in Global Africa: Transnational Health and Healing (pp. 213-240). Indianapolis: Indiana University Press.

McGilvray, J. C. (1981). The Quest for Health and Wholeness. German Institute for Medical Missions: Würzburg.

Narayan, D. (2000). Voices of the Poor: Can Anyone Hear Us? Oxford University Press.

Neumann, I. B. (2007). "A Speech That the Entire Ministry May Stand for," or: Why Diplomats Never Produce Anything New. International Political Sociology, 1(2), 183200. doi:10.1111/j.1749-5687.2007.00012.x

Olivier, J., \& Wodon, Q. (2012). Mapping, Cost, and Reach to the Poor of Faith-inspired Health Care Providers in sub-Saharan Africa. Strengthening the Evidence for Faithinspired Health Engagement in Africa, Volume 3. Health, Nutrition and Population (HNP) Discussion Paper. Washington, DC: World Bank.

Ottersen, O. P., Dasgupta, J., Blouin, C., Buss, P., Chongsuvivatwonga, V., Frenk, J., . . . Scheel, I. B. (2014). The Political Origins of Health Inequity: Prospects for Change. The Lancet, 383(9917), 630-667.

Pargament, K. I., Koenig, H. G., \& Perez, L. M. (2000). The Many Methods of Religious Coping: Development and Initial Validation of the RCOPE. Journal of Clinical Psychology, 56(4), 519-543.

Payne, R.A. (2001). Persuasion, Frames, and Norm Construction. European Journal of International Relations 7(1), 37-61.

Renner, J. (2013). Discourse, Normative Change and the Quest for Reconciliation in Global Politics. Manchester, New York: Manchester University Press.

Risse, T., Ropp, S. C., \& Sikkink, K. (Eds.). (1999). The Power of Human Rights. Cambridge, MA: Cambridge University Press.

Schmid, B., Thomas, E., Olivier, J., \& Cochrane, J. R. (2008). The Contribution of Religious Entities to Health in Sub-saharan Africa: Study commissioned by Bill \& Melinda Gates Foundation. Cape Town: African Religious Health Assets Programme.

Staples, A. L. S. (2006). The Birth of Development: How the World Bank, Food and Agriculture Organization, and World Health Organization Changed the World, 19451965. Kent, OH: The Kent State University Press.

Steffek, J. (2005). Incomplete Agreements and the Limits of Persuasion in International Politics. Journal of International Relations and Development, 8(3), 229-256.

Taylor, C. (2007). A Secular Age. Cambridge, MA: Belknap Press of Harvard University Press.

Walzer, M. (1994). Thick and Thin: Moral Arguments at Home and Abroad. Notre Dame, IN: University of Notre Dame Press. 
WHO. (1985). Handbook of resolutions and decisions of the World Health Assembly and the Executive Board. 26th to 37th World Health Assemblies, 51st to 74th sessions of the Executive Board. Geneva: World Health Organization.

WHO. (1998a) Executive Board. 101st Session. Geneva, 19-27 January 1998. Resolutions and Decisions. Annexes. EB101/1998/REC/1. Geneva: World Health Organization.

WHO. (1998b). Executive Board. 101st Session. Geneva, 19-27 January 1998. Summary Records. EB101/1998/REC/2. Geneva: World Health Organization.

WHO. (2006). Constitution of the World Health Organization. Supplement, Forty-fifth edition of 'Basic Documents'. Retrieved from www.who.int/governance/eb/who_constitution_en.pdf

WHO. (2008). Building From Common Foundations: The World Health Organization and Faith-Based Organizations in Primary Health Care. Retrieved from http://apps.who.int/iris/bitstream/10665/43884/1/9789241596626_eng.pdf?ua=1

WHO Regional Office for the Eastern Mediterranean. (1996). Health Promotion through Ismalic Lifestyles: The Amman Declaration. Alexandria: World Health Organization.

Wiener, A. (2007). Contested Meanings of Norms: A Research Framework. Comparative European Politics, 5(1), 1-17.

World Faiths Development Dialogue. (2012). Global Health and Africa: Assessing Faith Work and Research Priorities. Washington, DC. Retrieved from http://repository.berkleycenter.georgetown.edu/GlobalHealthandAfricaWFDDEdition.pdf

Zwingel, S. (2012). How Do Norms Travel? Theorizing International Women's Rights in Transnational Perspective. International Studies Quarterly, 56(1), 115-129. 